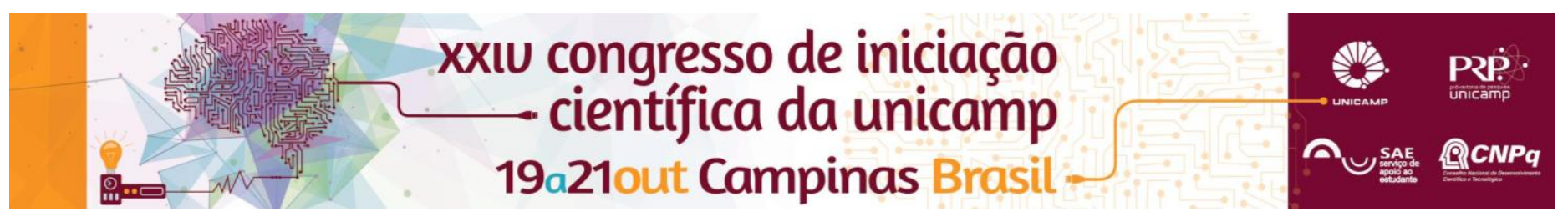

\title{
Bioprospecção em linhagens de Trichoderma spp. da floresta amazônica que inibem Pythium aphanidermatum por compostos orgânicos voláteis
}

\section{Dáfini Letícia Bruno*, Camila Cristiane Pansa*, Itamar Soares de Melo}

\section{Resumo}

O controle biológico vem sendo muito utilizado na agricultura moderna e os fungos do gênero Trichoderma são conhecidos por possuirem potencial no controle biológico. Portanto, o trabalho objetivou selecionar linhagens com potencial de inibição contra o fungo fitopatógeno Pythium aphanidermatum por meio da produção de compostos orgânicos voláteis, o qual permitiu selecionar 102 linhagens com potenciais de controle para o fitopatógeno.

\section{Palavras-chave:}

Cotrole biológico, antagonismo, fitopatógeno.

\section{Introdução}

Os fungos do gênero Trichoderma atuam como agentes de controle biológico de várias plantas cultivadas, (FORTES et al. 2007) e agem por diferentes mecanismos como a antibiose oriunda da produção de metabólitos tóxicos (WEINDLING, 1934) como os compostos orgânicos voláteis que realizam 0 antagonismo entre micro-organismo pela produção de substâncias voláteis (Benitez et al.,2004). O controle biológico é uma estratégia livre de riscos e tem sido empregada na agricultura para fungos patogênicos como Pythium spp. que promovem o apodrecimento radicular (STEPHENS; POWELL, 1982). Portanto, o presente trabalho teve como objetivo selecionar linhagens Trichoderma spp. isolados de solos da floresta amazônica com potencial de inibição para o fitopatógeno Pythium aphanidermatum por produção de compostos orgânicos voláteis.

\section{Resultados e Discussão}

Foram submetidas ao teste 253 linhagens de Trichoderma sp. obtidas a partir do meio de cultivo TSM (ELAD,1980) específico para isolamento do gênero. Com a sobreposição e união das bases das placas contendo o Trichoderma sp. e outra base contendo o fitopatógeno (Figura 1) incubadas a $26^{\circ} \mathrm{C}$ por 4 dias, obtiveram-se os valores da percentagem de inibição a partir do crescimento do fitopatógeno. Do total de linhagens avaliadas $40 \%$ apresentaram potencial de inibição contra $P$. aphanidermatum, onde $32 \%$ apresentaram taxas de 41 a $49 \%$ de inibição e $28 \%$ das linhagens apresentaram uma taxa igual e maior que $50 \%$ de inibição contra o fitopatógeno (Figura 2).

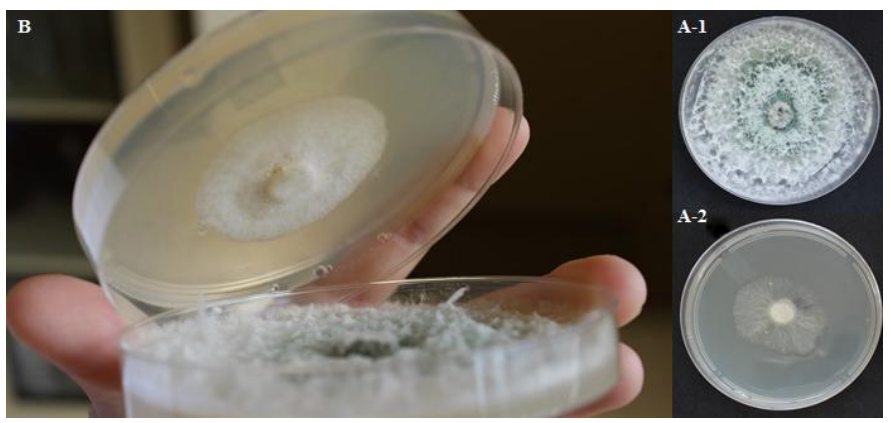

Figura 1. B- llustra a montagem do teste de compostos orgânicos voláteis. A-1 Fungo Trichoderma. A-2 Inibição do $P$. aphanidermatum.
Porcentagem de Inibição de $P$. aphanidermatum por Compostos Voláteis

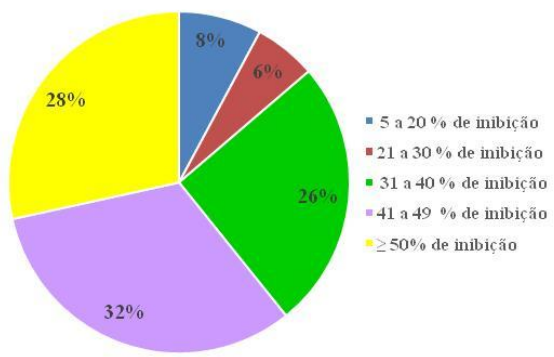

Figura 2. Valores de inibição de $P$. aphanidermatum por compostos orgânicos voláteis de Trichoderma spp.

Em estudos realizados por Khare et al., (2010) com produção de compostos orgânicos voláteis por linhagens de Trichoderma viride obtiveram uma taxa de $35 \%$ de inibição contra o fitopatógeno diferente dos resultados obtidos no presente trabalho que apresentou percentuais acima de $50 \%$, e uma das linhagens promoveu a inibição de $84 \%$ do fitopatógeno.

\section{Conclusões}

A partir dos resultados obtidos conclui-se que linhagens do gênero Trcihoderma spp. isolados de solos amazônicos possuem potencial de inibição contra $P$. aphanidermatum por produção de metabólitos orgânicos voláteis sendo uma fonte promissora em estudos para o controle biológico do fitopatógeno.

\section{Agradecimentos}

Á FAPESP pelo financiamento e a Embrapa Meio Ambiente que permitiu a execução do trabalho.

BENÍTEZ, T; RINCÓN, A.M; LIMÓN, M.C; CODÓN, A.C. Biocontrol mechanisms of Trichoderma strains. International Microbiology. V.7, p. 249260, 2004.

KHARE, A.; SINGH, B. K.; UPADHYAY, R. S. Biological control of Pythium aphanidermatum causing damping-off mustard by mutants of Trichoderma viride 1433. Journal of Agricultural Technology. v.6 p.231-243. 2010. 